\title{
MULTIMEDIA INTERAKTIF BAGI SISWA BERKEBUTUHAN KHUSUS
}

\author{
Mukhammad Luqman Hakim ${ }^{1}$ \\ ${ }^{I}$ Fakultas Tarbiyah, Institut Agama Islam Negeri Kediri \\ mukh.luqman@iainkediri.ac.id
}

Naskah diterima: 3 Maret, 2020, direvisi: 20 Maret, 2020, diterbitkan: 31 Maret, 2020

\begin{abstract}
The aim of this research is to apply interactive multimedia to students special needs. The use of interactive multimedia in the learning of Islamic Religious Education to provide different learning experiences for students special needs. The material included in interactive multimedia is "Mengenal Malaikat ALLAH SWT". This research method uses a qualitative descriptive approach. This approach is intended to record the use of media in the learning of Islamic Religious Education at SLB Nurul Ikhsan Ngadiluwih which is conducted on 10 students, Islamic subject teachers and Principals who are the subjects. Indicators of the use of instructional media include planning, implementing and evaluating learning. As a qualitative descriptive study, the data collection method was carried out using interviews and observations. From this study found several things namely students are more motivated in learning, this is because the appearance of an interesting media and is equipped with an animation about the explanation of the material; students can learn anywhere and anytime because learning media is portable; the teacher gets ease in delivering subject matter.
\end{abstract}

Keywords: Interactive multimedia, students special needs, mentally disabled.

\begin{abstract}
ABSTRAK
Tujuan dari penelitian ini adalah untuk menerapkan multimedia interaktif kepada siswa berkebutuhan khusus. Penggunaan multimedia interaktif dalam pembelajaran Pendidiakan Agama Islam untuk memberikan pengalaman belajar berbeda kepada siswa luar biasa. Materi yang dimasukkan dalam multimedia interaktif adalah materi Mengenal Malaikat Allah SWT. Metode penelitian ini menggunakan pendekatan deskriptif kualitatif. Pendekatan ini dimaksudkan untuk merekam pemanfaatan media dalam pembelajaran Pendidikan Agama Islam di SLB Nurul Ikhsan Ngadiluwih yang dilakukan kepada 10 siswa, guru mata pelajaran Pendidikan Agama Islam dan Kepala Sekolah yang menjadi subyeknya. Indikator pemanfaatan media pembelajaran meliputi perencanaan, pelaksanaan dan penilaian pembelajaran. Sebagai penelitian deskriptif kualitatif, metode pengumpulan data dilakukan dengan menggunakan, wawancara dan observasi. Dari penelitian ini ditemukan beberapa hal yaitu Siswa lebih termotivasi dalam beajar, hal ini dikarenakan tampilan media yang menarik dan dilengkapi dengan animasi tentang penjelasan materi; siswa bisa belajar dimana saja dan kapan saja karena media pembelajaran bersifat portable; guru mendapatkan kemudahan dalam penyampaian materi pelajaran.
\end{abstract}

Kata Kunci: Multimedia interaktif, siswa berkebutuhan khusus, tunagrahita.

\section{PENDAHULUAN}

Sekolah luar biasa atau yang akrab disebut dengan SLB ialah sekolah yang melaksanakan proses pembelajaran khusus untuk para siswa yang memiliki kondisi berbeda dengan siswa pada umumnya. Kondisi yang berbeda inilah yang mengharuskan ada penanganan berbeda dalam proses pembelajaran. Dalam UDD 1945 pasal 31 ayat 1 ditegaskan, bahwa tiap-tiap warga negara berhak mendapat pendidikan. Menurut Yustiani (2009) hak mendapatkan pendidikan ini tanpa terkecuali, yaitu tidak melihat kondisi calon peserta 
didik, baik dalam kondisi normal secara fisik maupun dalam kondisi memiliki kelainan, seperti menyandang cacat dalam penglihatan atau tuna netra, tuna rungu, tuna grahita, tuna daksa maupun tuna laras.

Asas dari proses pembelajaran efektif dan efisien haruslah menyesuaikan karakteristik dari peserta didiknya. Proses pembelajaran di sekolah luar biasa sangatlah berbeda dengan sekolah reguler. Terdapat perbedaan dalam segi penyaluran materi dari pendidik ke peserta didik, media pembelajaran yang digunakan serta durasi atau waktu yang diperlukan dalam proses pembelajaran.

Pemanfaatan media pembelajaran sebagai salah satu alternatif yang bisa digunakan dalam penyaluran materi dari guru ke peserta didik. Kualitas pendidikan bisa ditingkatkan dengan penggunaan media pembelajaran. Salah satu prinsip penggunaan media pembelajaran yaitu sebagai penyaan persepsi pesan yang disampaikan guru kepada siswa. Media pembelajaran harus dirancang dan dikembangkan sesuai dengan karakteristik pengguna media. Hal ini dilakukan untuk bisa mengoptimalkan proses penyaluran pesan dari guru ke peserta didik. (Sudjana \& Rifa'i, 2011)

Materi pelajaran yang akan dikemas ke dalam media pembelajaran juga harus disesuaikan dengan pengguna media, hal ini sama halnya dengan desain media pembelajaran. Materi dalam media pembelajaran harus bersifat singkat, padat dan mudah dipahami oleh pengguna media. Hal ini dimaksudkan yaitu agar pengguna media bisa belajar secara mandiri ketika menggunakan media pembelajaran. Penggunaan kalimat dan komposisi materi harus benar-benar diperhatikan dalam mengembangkan sebuah media pembelajaran. (Mayer, 2003) (Sadiman, 2007) (Diergarten, Möckel, Nieding, \& Ohler, 2017)

Pemanfaatan media pembalajaran saat ini masih belum ada yang spesifik diperuntukkan untuk anak berkebutuhan khusus. Pemanfaatan media hanya sebatas digunakan untuk siswa normal dengan beberapa karakteristik yang hampir sama. Dari beberapa penelitian terdahulu memberikan kesimpulan pemanfaatan multimedia pembelajaran interaktif bisa meningkatkan motivasi belajar dan berdampak pada peningkatan hasil belajar. (Nopriyanti \& Sudira, 2015) (Dewi, 2015) (Alannasir, 2016) (Anwas, 2015) (Sa'adah, Pramono, \& Suharso, 2017)

Hasil dari penelitian terdahulu masih belum ada yang menjelaskan secara spesifik terkait pemanfaatan multimedia pembelajaran interaktif untuk siswa yang mempunyai kebutuhan khusus. Berdasarkan permasalahan yang dihadapi peneliti berkeinginan untuk melakukan penelitian terkait pemanfaatan media pembelajaran khusus untuk siswa yang memiliki kebutuhan khusus. Media yang akan dimanfaatkan diperuntukkan khusus untuk siswa yang memiliki spesial.

SLB Nurul Ikhsan Ngadiluwih merupakan salah satu sekolah luar biasa yang berada di Kabupaten Kediri Jawa Timur. SLB Nurul Ikhsan berdiri atas inisiatif dari para pimpinan yayasan untuk mewadahi anak-anak yang memiliki kebutuhan khusus agar tetap mendapatkan fasilitas pendidikan yang layak. SLB Nurul Ikhsan Ngadiluwih terdapat dua jenjang tingkat pendidikan yaitu Sekolah Dasar Luar Biasa (SDLB) dan Sekolah Menengah Pertama Luar Biasa (SMPLB). Dari kedua tingkatan pendidikan tersebut masih diklasifikasikan lagi menjadi beberapa jenis kelas.

Pengklasifikasian kelas disesuaikan dengan karakteristik yang dimiliki oleh setiap peserta didik. SLB Nurul Ikhsan terdapat lima pengklasifikasian keluarbiasaan siswanya. Pengklasifikasian keluarbiasaan di SLB Nurul Ikhsan Ngadiluwih diantaranya yaitu kelas tunanetra, kelas tunarungu, kelas tunagrahita, kelas tunadaksa dan kelas autis. Pengklasifikasian dilaksanakan agar lebih bisa mengoptimalkan proses pembelajaran. 
Disetiap ruang kelas di SLB Nurul Ikhsan Ngadiluwih disediakan perangkat LCD yang memungkinkan untuk menayangkan video pembelajaran dan media yang lainnya.

Berdasarkan pemaparan kondisi di atas, peneliti berkeinginan untuk menerapkan media pembelajaran dan proses belajar mengajar di SLB Nurul Ikhsan. Penelitian ini bertujuan untuk memaparkan hasil pengaplikasikan media pembelajaran berbasis Dekstop dengan menggunakan Aplikasi "SECIL" dalam mata pelajaran Pendidikan Agama Islam dengan materi Malaikat dan Tugasnya.

\section{METODOLOGI}

Penelitian ini menggunakan pendekatan deskriptif kualitatif. Pendekatan ini dimaksudkan untuk merekam pemanfaatan media dalam pembelajaran Pendidikan Agama Islam di SLB Nurul Ikhsan Ngadiluwih yang dilakukan kepada 10 siswa, guru mata pelajaran Pendidikan Agama Islam dan Kepala Sekolah yang menjadi subyeknya. Indikator pemanfaatan media pembelajaran meliputi perencanaan, pelaksanaan dan penilaian pembelajaran. Sebagai penelitian deskriptif kualitatif, metode pengumpulan data dilakukan dengan menggunakan, wawancara dan observasi.

\section{HASIL DAN DISKUSI}

Berdasarkan hasil wawancara dan observasi yang dilaksanakan di SLB Nurul Ikhsan Ngadiluwih dikemukakan beberapa penjelasan sebagai berikut: Siswa SLB Nurul Ikhsan Ngadiluwih mayoritas siswanya berasal dari desa setempat yakni Ngadiluwih, Manisrenggo dan Rembang namun ada juga salah satu murid yang berasal dari Kota Kediri. SLB Nurul Ikhsan Ngadiluwih merupakan satu satunya Sekolah Luar Biasa di Ngadiluwih. Terletak di perkampungan warga yang lumayan jauh dari jalan raya, membuat situasi belajar lebih kondusif, terlebih ketika peneliti menggunakan model pembelajaran interaktif yang akan membuat proses belajar mengajar lebih menyenangkan.

Proses belajar mengajar siswa lebih bisa diatur karena jumlah siswa lumayan sedikit meskipun ada beberapa siswa yang sulit dikendalikan. Namun guru tidak langsung memarahi siswa jika ada yang kurang bisa diatur. Karena kondisi siswa sendiri yang memiliki kebutuhan khusus dan perlu perhatian dari guru. Siswa juga sangat ramah kepada guru. Meskipun mempunyai keterbatasan khusus, semangat belajar siswa sangat tinggi. Hal ini terbukti dengan diraihnya beberapa prestasi oleh siswa SLB Nurul Ikhsan Ngadiluwih.

Pemilihan media pembelajaran haruslah mencakup beberapa faktor agar pembelajaran bisa berjalan efektif dan efisien. Berikut ini alasan peneliti memilih multimedia pembelajaran Secil untuk diterapkan di SLB Nurul Ikhsan Ngadiluwih berdasarkan faktor yang dijelaskan oleh Djamarah (2010), faktor tersebut meliputi:

Media pembelajaran harus bersifat objektif karena media pembelajaran yang akan diterapkan berdasarkan pada kajian riset atau penelitian terdahulu. Hal ini diperlukan untuk mengetahui kelemahan atau kelebihan media pembelajaran. Dalam penelitian ini, peneliti terlebih dahulu melakukan kajian riset terdahulu sebelum melakukan pemanfaatan media. Beberapa hasil kajian riset terdahalu menjelaskan bahwa multimedia pembelajaran Secil efektif diterapkan untuk kelas rendah, yaitu kelas 1-3 jenjang sekolah dasar. Konten yang ada dalam multimedia pembelajaran Secil mudah dipahami oleh anak dan tampilan multimedia yang mudah digunakan.

Materi yang akan disampaikan dalam multimedia pembelajaran Secil sudah sesuai dengan kurikulum SLB Nurul Ikhsan Ngadiluwih. Materi terkait nama Malaikat dengan 
tugasnya terdapat dalam silabus. Struktur materi yang tersaji dalam multimedia pembelajaran Secil terstruktur. Materi disajikan dalam bentuk audio dan teks yang mudah dipahami. Berikut ini struktur materi yang ada dalam multimedia pembelajaran Secil.

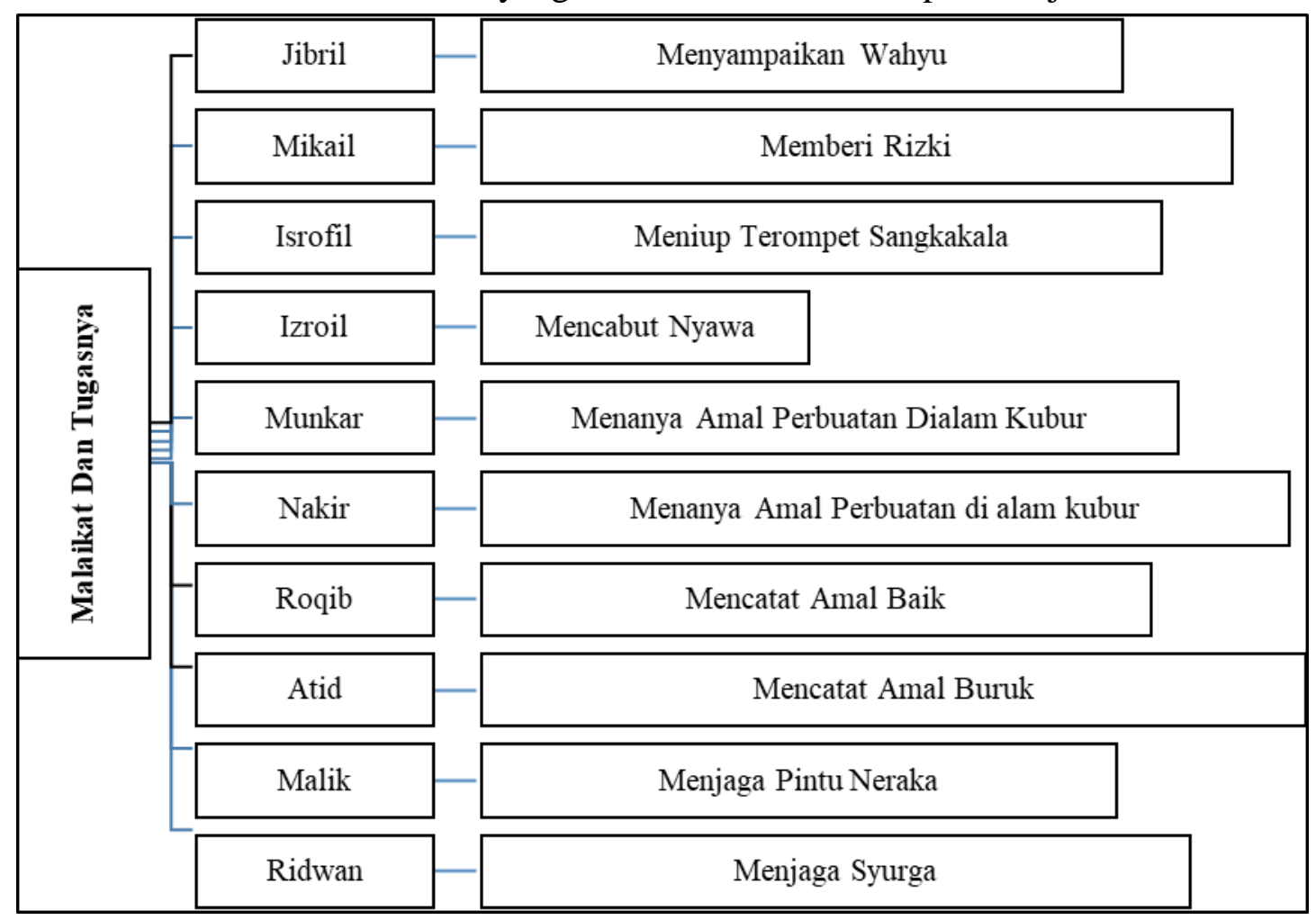

Gambar 1: Struktur Materi

Audien atau pengguna media adalah siswa yang memiliki kebutuhan khusus, yakni anak tunagrahita. Multimedia pembelajaran yang digunakan mudah digunakan oleh siswa berkebutuhan khusus dengan pendampingan oleh guru. Pendampingan dalam hal ini berupa cara penggunaan multimedia dan penekanan materi yang dianggap penting. Peran guru dalam pemanfaatan multimedia pembelajaran Secil sangat besar, mulai dari persiapan alat pemutar atau Player, penggunaan multimedia sampai pada proses evaluasi materi yang diberikan kepada siswa berkebutuhan khusus.

Tugas-tugas yang diberikan atau dibebankan kepada peserta didik harus mempertimbangkan kemampuan peserta didik itu sendiri. Dalam penelitian ini tugas disesuaikan dengan anak kebutuhan khusus yakni anak tunagrahita. Dalam pemberian tugas pembelajaran disesuaikan dengan sikap, pengetahuan dan keterampilan sebagai pribadi maupun anggota masyarakat dalam mengadakan hubungan timbal balik dengan lingkungan sosial maupun budaya sekitar.

Dalam pemberian tugasnya disesuaikan dengan tingkat perkembangaan kemampuan fungsional dari setiap siswa, meliputi sensori motor, kreativitas, interaksi sosial siswa, dan bahasa siswa dengan memberikan kapasitas pembelajaran yang pas. Dalam ranah afektif disesuaikan dengan kondisi siswa dan keterbatasan siswa, siswa diberikan jenis-jenis permainan memecahkan masalah, bisa dengan pemecahan masalah melalui permainan keterampilan, karena tunagrahita cenderung lemah dalam kognitifnya maka untuk mendukung kognitifnya pembelajaran dilakukan dengan permainan yang menarik sehingga peserta didik dalam menangkap pembelajaran lebih mudah. Dan untuk mempertimbangkan ranah psikomotornya peneliti melihat dari kemampuan interaksi 
peserta didik dalam melakukan permainan, selain itu cakupan pembelajaran meliputi: kecakapan hidup umum dan kerampilan kerja

Analisis yang sudah dilakukan didapatkan konsep pembelajaran yang harus di sampaikan peserta didik pada pembelajaran multimedia ini adalah memfokuskan pada keterampilan kematangan menolong diri atau keterampilan kehidupan sehari-hari dan akademik sosial (seperti membaca, menghitung). Untuk mencapai hasil belajar dengan multimedia maka ABK perlu mempelajari suatu materi dengan mengulang-ulang dan diberikan contoh dalam kehidupan sehari-hari secara konkrit sebagai bekal mengenal lingkungannya serta latihan memelihara diri dan bebrapa ketarampilan sederhana. Dalam menyampaikan materi anak ABK tunagrahita tidak bisa secara cepat menangkap materi oleh karenanya maka pembelajaran tidak akan efektif jika diberikan materi yang cukup banyak dan tidak di ulang-ulang, dan peneliti juga menghindari pembelajaran akademik, penggunaan bahasa yang berlebihan.

Dalam proses implementasi kami bertujuan agar siswa dapat memperhatikan atau fokus dengan materi yang telah kami sampaikan, agar siswa berkebutuhan khusus termotivasi dengan model pembelajaran yang lebih bervariasi. Pembelajaran di kelas ini tidak luput dengan perangkat pembelajaran yang sudah tersedia di sekolah ini. Dan perlu diingat bahwa implementasi pembelajaran berbasis aplikasi ini selarasas dengan Rencana Program Pembelajaran serta silabus.

Teknologi yang tersedia di SLB Nurul Ikhsan Ngadiluwih yaitu Laptop, LCD, Spiker aktif dan sejenisnya. Penggunaan teknologi tidak selalu digunakan dalam proses pembelajaran, hanya digunakan dalam hal tertentu seperti ketika peneliti ingin melakukan penelitian pemanfaatan multimedia pembelajaran Secil pihak sekolah langsung memperkenankan menggunakan fasilitas tersebut. Kondisi sekolah yang terletak ditengah perkampungan warga membuat situasi belajar yang kondusif dengan lingkungan yang tenang.

Pemanfaatan multimedia pembelajaran Secil meliputi proses perencanaan, pelaksanaan dan penilaian pembelajaran. Pada proses perencanaan multimedia pembelajaran Secil, peneliti melakukan langkah-langkah sebagai berikut:

Langkah pertama dalam perencanaan multimedia pembelajaran yaitu menentukan tujuan pembelajaran. Tujuan pembelajaran dari multimedia pembelajaran adalah Siswa dapat mengenal nama-nama malaikat beserta tugasnya. Setelah menentukan tujuan pembelajaran peneliti menentukan materi-materi penting yang ada di dalam multimedia pembelajaran. Materi penting ini disajikan dengan semudah mungkin untuk dipahami para siswa.

Langkah kedua yaitu peneliti membuat alur tata cara pemanfaatan multimedia pebelajaran. Tata cara pemanfaat dibuat untuk memudah guru atau wali murid dalam membantu siswa dalam belajar menggunakan multimedia pembelajaran. Dalam tata cara penggunaan multimedia pembelajaran juga ditentukan bagaimana proses evaluasi setelah penggunaan multimedia pembelajaran Secil.

Proses pelaksanaan pemanfaatan multimedia pembelajaran Secil berbasis dekstop, peneliti menggunakan software Emulator untuk menghubungkan system android kemudian dapat diakses kedalam dekstop PC/ Laptop. Dalam implementasi media dan teknologi berbasis aplikasi ini, guru membutuhkan alat bantu LCD Proyektor sebagai sarana pendukung dalam menerapkan multimedia pembelajaran Secil.

Proses penilaian dari pemanfaatan multimedia Secil ini menggunakan sistem tanya jawab. Sistem tanya jawab dipilih peneliti dengan mempertimbangkan karakteristik dari peserta didik. Selain menggunkan tanya jawab, proses penilaian pemahaman 
terhadap materi Malaikat dan Tugasnya juga sudah tersedia di Aplikasi multimedia pembelajaran Secil, yaitu dengan mencocokan nama malaikat beserta tugasnya. Selama proses pembelajaran dengan menggunakan multimedia pembelajaran Secil sepenuhnya dibantu oleh guru, mulai dari memilih menu, materi sampai pada menjodhkan atau mencocokkan gambar. Berikut ini storyboard multimedia pembelajaran Secil.

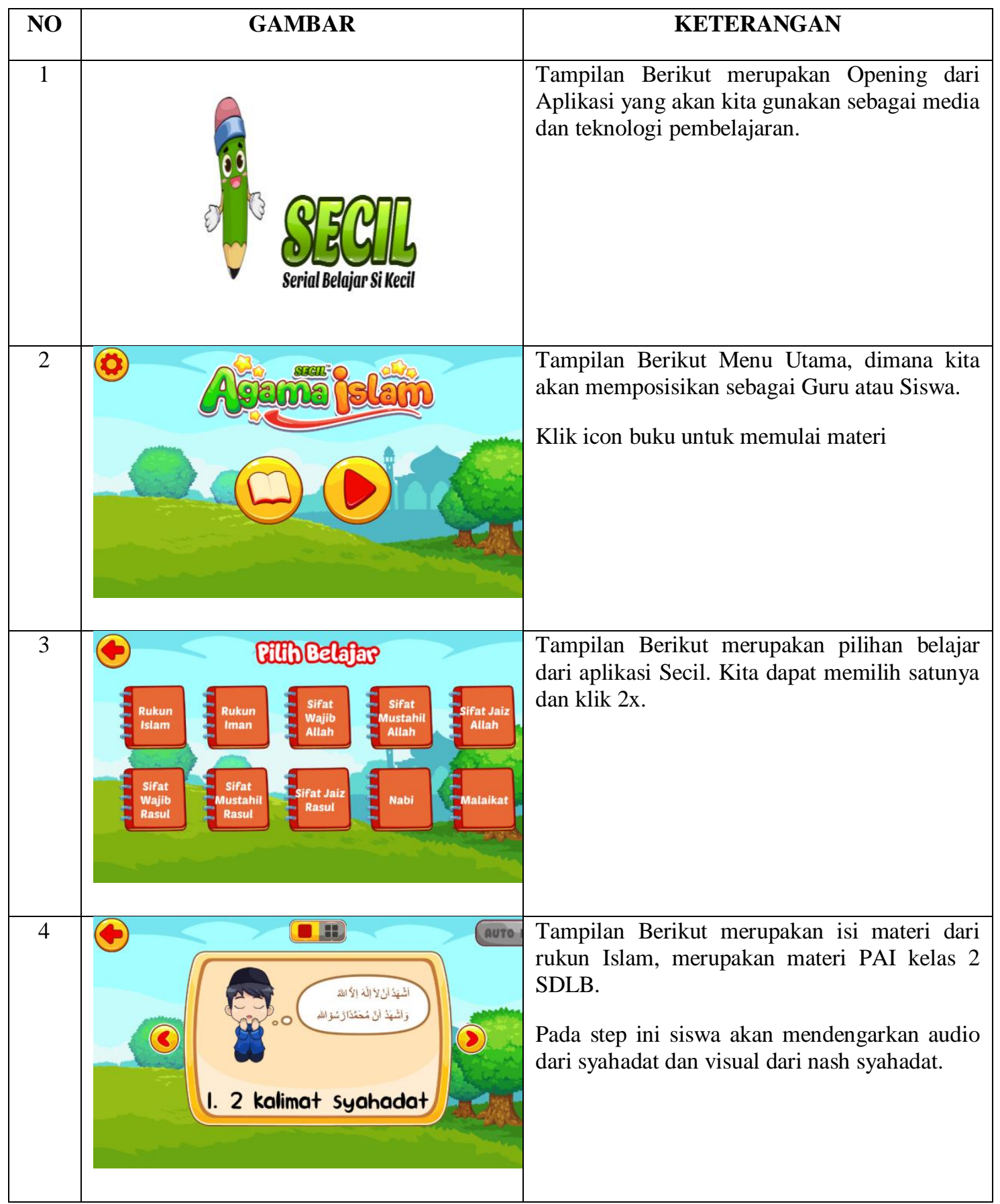




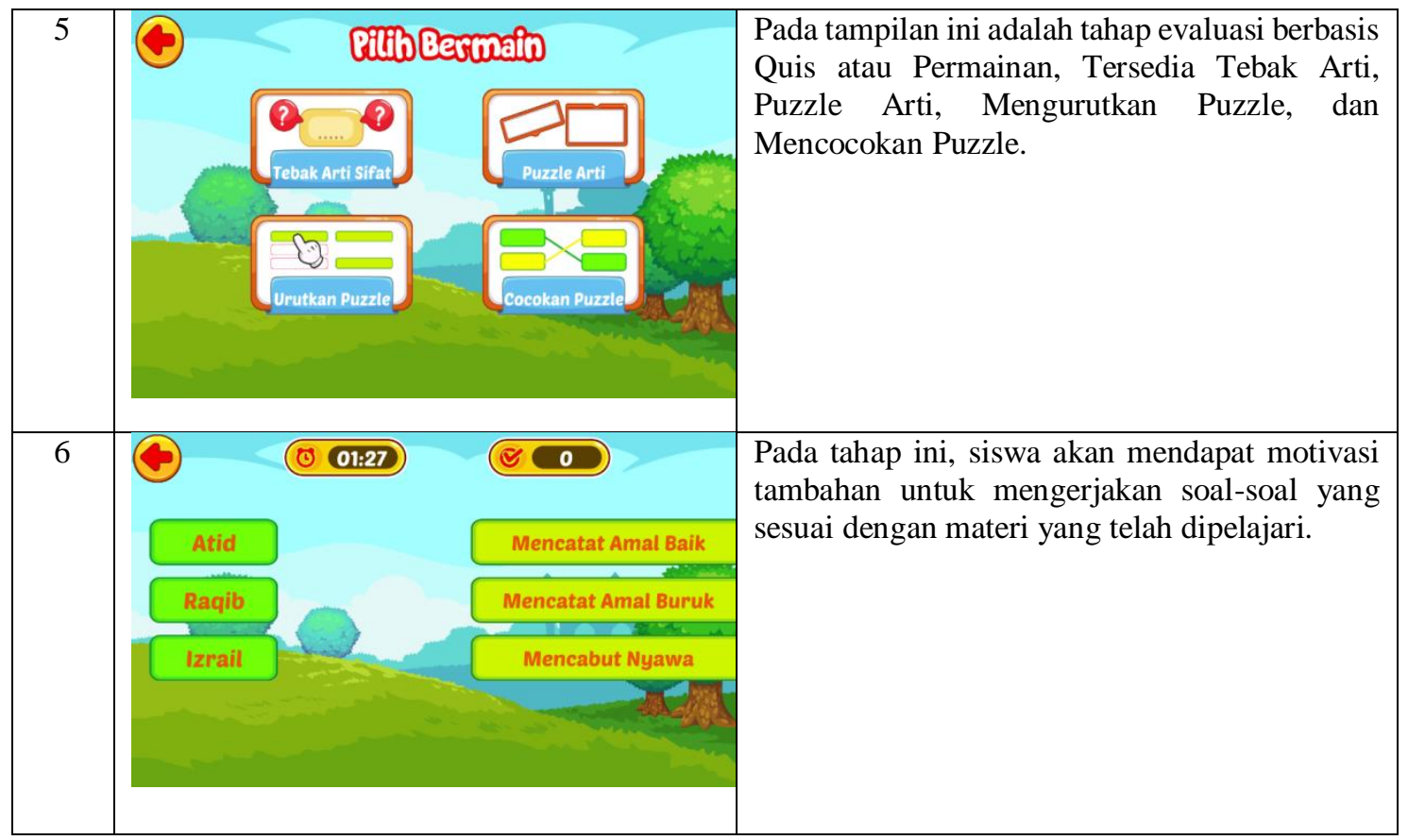

Untuk mengetahui tingkat keefektifan multimedia pembelajaran Secil, peneliti melakukan wawancara dengan siswa, guru, dan kepala sekolah. Menurut para siswa, siswa merasa senang belajar dengan menggunakan multimedia pembelajaran. Siswa mendapatkan pengalaman belajar baru dengan menggunakan multimedia pembelajaran. Siswa merasa termotivasi dalam belajar. Siswa merasa terhibur dan senang dalam penjelasan materi, karena materi dalam multimedia pembelajaran Secil disajikan dengan audio, teks dan animasi.

Menurut tanggapan guru, multimedia pembelajaran Secil bisa diterapkan di jenjang sekolah luar biasa, namun dalam pemanfaatannya harus dibimbing sepenuhnya oleh guru. Para siswa mulai mengenal penggunaan Smartphone tidak hanya untuk bermain game saja, melainkan bisa untuk sarana belajar yang menyenangkan. Multimedia pembelajaran Secil.

Tanggapan dari kepala sekolah, multimedia pembelajaran Secil sangat cocok diterpakan di sekolah dasar luar biasa. Menurut kepala sekolah siswa mudah dalam belajar karena multimedia pembelajaran Secil bisa digunakan kapan saja dan dimana saja. Siswa mendapatkan pengalaman belajar baru. Namun dalam penggunaannya, siswa harus mendapatkan pendampingan secara penuh oleh guru maupun wali murid. Sebaiknya dikembangkan lagi multimedia pembelajaran untuk materi-materi yang lain.

\section{KESIMPULAN}

Berdasarkan hasil pemanfaatan multimedia pembelajaran Secil di SLB Nurul Ikhsan Ngadiluwih ditemukan beberapa hal diantaranya yaitu: siswa lebih termotivasi dalam beajar, hal ini dikarenakan tampilan media yang menarik dan dilengkapi dengan animasi tentang penjelasan materi. Siswa bisa belajar dimana saja dan kapan saja karena media pembelajaran bersifat portable. Guru mendapatkan kemudahan dalam penyampaian materi pelajaran. 


\section{BIBLIOGRAPHY}

Alannasir, W. (2016). Pengaruh Penggunaan Media Animasi Dalam Pembelajaran Ips Terhadap Motivasi Belajar Siswa Kelas IV Sd Negeri Mannuruki. Journal of Educational Science and Technology (EST), 2(2), 81-90. https://doi.org/10.26858/est.v2i2.2561

Anwas, O. M. (2015). Pemanfaatan Teknologi Informasi dan Komunikasi pada Pesantren Rakyat Sumber Pucung Malang. Jurnal Pendidikan dan Kebudayaan, 21(3), 207220-220. https://doi.org/10.24832/jpnk.v21i3.187

Dewi, T. A. (2015). Implementasi Multimedia Interaktif Dalam Pembelajaran Ekonomi Di Sekolah. Promosi: Jurnal Program Studi Pendidikan Ekonomi, 3(2). https://doi.org/10.24127/ja.v3i2.328

Diergarten, A. K., Möckel, T., Nieding, G., \& Ohler, P. (2017). The impact of media literacy on children's learning from films and hypermedia. Journal of Applied Developmental Psychology, $48, \quad 33-41$. https://doi.org/10.1016/j.appdev.2016.11.007

Djamarah, Syaiful Bahri. (2010) Strategi Belajar Mengajar. Jakarta: Rineka Cipta.

Mayer, R. E. (2003). The promise of multimedia learning: Using the same instructional design methods across different media. Learning and Instruction, 13(2), 125-139. https://doi.org/10.1016/S0959-4752(02)00016-6

Nopriyanti, N., \& Sudira, P. (2015). Pengembangan multimedia pembelajaran interaktif kompetensi dasar pemasangan sistem penerangan dan wiring kelistrikan di SMK. Jurnal Pendidikan Vokasi, 5(2), 222-235. https://doi.org/10.21831/jpv.v5i2.6416

S, Y. (2009). Pendidikan Agama Pada Sekolah Luar Biasa (Studi Kasus SDLB Dharma Asih Kota Pontianak, Kalimantan Barat). Analisa: Journal of Social Science and Religion, 16(2), 257-270. https://doi.org/10.18784/analisa.v16i2.53

Sa'adah, I., Pramono, S. E., \& Suharso, R. (2017). Pengembangan Media Video Motion Graphic Sejarah Pemerintahan Herman Willem Daendels (1808-1811) dalam Pembelajaran Sejarah Indonesia Untuk Meningkatkan Minat Belajar Siswa Untuk SMA. Indonesian Journal of History Education, 5 (1). Diambil dari https://journal.unnes.ac.id/sju/index.php/ijhe/article/view/19904

Sadiman, A. S. (2007). Media Pendidikan Pengertian, Pengembangan dan Pemanfaatannya. Jakarta: PT. Raja Grafindo Persada.

Sudjana, N., \& Rifa'i, A. (2011). Media Pengajaran. Bandung: Sinar Baru Algesindo. 